\title{
Study on Third-Party supervision of Major Ecological Ecological Projects Auditing Based on Principal-agent Theory
}

\author{
Zhao Liang, $^{1, *}$, Zheng Chuiyong ${ }^{1}$ \\ ${ }^{1}$ Business School of HOHAI University Nanjing Jiangsu 210098, China
}

\begin{abstract}
Without considering the existence of third-party audit supervision and considering the existence of third-party audit supervision, the principal-agent model of major engineering audits between government and audit organizations was constructed. The analytical solutions under various hypothetical conditions were analyzed for the government. The optimal incentive policy for major engineering audits provides the basis. The analysis results prove that, the introduction of third-party units for audit supervision can effectively stimulate audit behavior, reduce information asymmetry, and create higher engineering quality and audit quality in the process of major engineering audit.
\end{abstract}

\section{INTRODUCTION}

With the rapid development of China's social economy, the proportion of major Ecological Projects in social fixed assets investment is increasing, especially since the reform and opening up. China has started a large number of major Ecological Projects such as the three Gorges Project, the South-to-North Water transfer Project, the Qinghai-Tibet Railway, the high-speed railway, the urban rail transit. It has played an important role in promoting economic growth, promoting social progress, improving the people's livelihood environment and achieving strategic objectives, but it has also caused problems such as poor decision-making, low investment efficiency and poor comprehensive benefits, and has even led to serious problems of corruption. It seriously affects and restricts the coordinated and sustainable development of our social, economic and ecological environment. As the main body of the audit supervision system of major Ecological Projects in our country, government audit institutions play a more and more important role in ensuring the efficiency and benefit of investment in major Ecological Projects and maintaining the healthy operation of the economy and society. However, in recent years, people from all walks of life pay more and more attention to audit, and the expectations of audit institutions and their related practitioners are higher and higher. The quality and clean government risks of government investment audit are also increasing. Therefore, objectively and accurately, in order to reflect and evaluate the audit work of major Ecological Projects on the basis of strengthening the internal control of project investment audit, it is necessary to introduce institutions or individuals that have no interest in audit matters to re-supervise government audit behavior, audit process and audit results. That is to say, third party supervision, which has become the power to strengthen supervision and restrict government audit, can contribute to these tasks which is important way to guard against the risk of government audit.

\section{THE CONNOTATION AND RESEARCH STATUS OF THIRD PARTY SUPERVISION OF MAJOR PROJECT AUDIT}

"Major project audit" refers to the use of appropriate procedures and methods by independent full-time audit institutions and auditors, taking major project audit activities as objects and in accordance with relevant laws and regulations or certain standards, To supervise, analyze and evaluate the economy, efficiency, effectiveness and fairness in the construction and management of major Ecological Projects, and to supervise the implementation of the public management responsibilities of the major project investment management bodies, In order to promote its improvement of project construction and management, we improve the performance of the use of funds to achieve a harmonious development of economic, social and ecological benefits of the whole process of supervision and evaluation activities, and make corresponding reports. As the public pays more and more attention to the audit affairs, the expectations of the audit institutions and their related practitioners are also becoming higher and higher. The issues of "audit who will audit" and "audit who supervise" have been put on the audit agenda. In order to ensure the exercise of audit power in the sun, the project audit must also accept the supervision of "third party supervision". At present, some scholars have carried on the thorough research to the engineering audit, for example, Calder (1997) has

\footnotetext{
$\overline{\text { * Corresponding author: zhaoliang2019 } @ 126 . c o m ~}$
} 
carried on the research to the construction quality audit supervision, thinks that the quality supervision is a systematic, independent inspection behavior, The main determination is whether the quality assurance measures and the associated effectiveness are consistent with the plan, and whether the plan implementation is effective and whether the applicable objectives are achieved [1]. Jergeas (2002) studied the efficiency of large-scale industrial building construction, and put forward a set of methods of engineering efficiency audit and measurement, such as planning management system and cost tracking system [2]. Wyse (2005) proposed that contract audit and real-time cost tracking audit are very important [3]. Khaled (2005) proposed that the problems of project delay and budget overrun could be eliminated or alleviated if proper attention was paid to the preconstruction stage of the project. Alexia (2007) proposed that audit has the function of controlling the engineering project, and demonstrated it from the scope of audit, audit responsibility and audit verification of risk [5]. From the above literature, scholars at home and abroad have studied the project audit from different angles, and achieved fruitful results, but lack of major project audit third party supervision research literature. Summing up the previous research results, we can see that the audit of major Ecological Projects is basically carried out in accordance with the following procedures: the owner entrusts the relevant units to carry out the project construction, and the government entrusts the audit organization to audit the project. It seems that the procedure and mechanism design are very perfect, but in the design of this mechanism, the audit institutions lack effective supervision or supervision in place, which makes the public have doubts about whether the project audit results are scientific, reasonable and objective and correct. It can not effectively solve the collusion and moral hazard of audit institutions. So far, "audit who audit", "audit who to supervise" and other thinking. In view of the need of continuous construction and audit of major Ecological Projects, the following third-party audit model of major engineering audit is constructed:

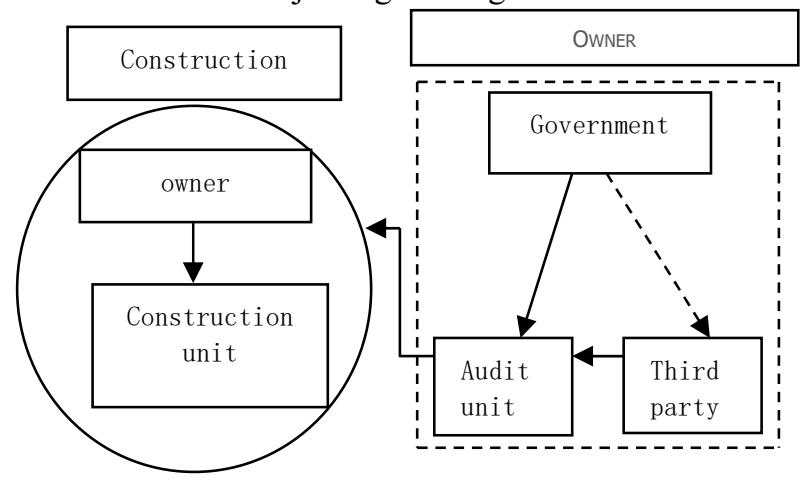

Fig. 1. Third-party supervision model of major engineering audit.

Compared with traditional engineering audit, a second audit organization is added to the third-party supervision model of major project audit. Concretely speaking, the owner entrusts a certain unit to carry on the project construction management. However, the government entrusts the independent audit department to carry on the audit to the entire project, at the same time.
The government entrusts the independent third party to carry on the audit supervision to the audit department. Through independent third-party audit supervision, we can ensure the correctness, regularity and scientific nature of the whole project audit work, thus effectively make up for and solve the problems of "audit who audit" and "audit who supervise" and so on.

Based on the principal-agent theory in game theory, this paper focuses on the principal-agent problem arising from the third-party supervision of major project audit. It can be seen that there are two principal-agent relationships between the government, the audit department and the third supervision organization in the audit module: the principal-agent relationship between the government and the audit department. The principalagent relationship is between the government and thirdparty organizations. When the behavior of audit department can not be observed by the government, there will be information asymmetry between the government and audit department. Driven by the pursuit of maximization of its own interests, audit department may choose to be lazy, and "moral hazard" will result. The government entrusts the third party organization to carry on the supervision audit to the audit department, the purpose is to reduce the information asymmetry, in order to raise the audit department's effort degree, causes the project audit quality to obtain the obvious enhancement.

\section{THE PRINCIPAL-AGENT MODEL OF MAJOR PROJECT AUDIT}

\subsection{Principal-agent model without consideration of audit supervision}

Without taking into account the existence of third-party oversight, the principal-agent model between the Government and the audit department is as follows:

\subsection{1 basic assumptions}

Assumption 1: assume that there is a client (government) and an agent (audit department), the audit department in order to complete the audit task entrusted by the government, select the level of effort $e(e \geq 0)$, effort cost is $C(e)=\frac{1}{2} b e^{2}, b>0$ in which the effort cost coefficient.

Assumption 2: assume that the audit department's effort output is $\pi$, and satisfied $\pi=e+\varepsilon, \varepsilon$ is an exogenous random variable, determined by the natural state, followed by the normal distribution of the mean value 0 and the variance $\sigma^{2}$, that is $\mathcal{E} \sim N\left(0, \sigma^{2}\right)$.

Assumption 3: assume that the government is riskneutral, the audit department is risk-averse, and a linear incentive contract is adopted between the government and the audit department $S(\pi)=\alpha+\beta(\pi-\alpha), \alpha$ which is the fixed income of the audit department ( $\pi$ independent of output) and the incentive intensity $\beta(0 \leq e \leq 1)$. Under normal circumstances, the audit 
department can make the output reach, by improving its own level of effort, it can also make the output greater than the excess profit, $\pi>\alpha$, therefore, based on the maximization of its own interests, Rational audit departments will choose a greater level of effort $\alpha$. In addition, it can be seen from the formula $S(\pi)=\alpha+\beta(e+\varepsilon-\alpha)$ that the revenue of the audit department is affected by the random variable $\varepsilon$.

Assumption 4: assume that the audit department is risk-averse, and its utility function has the same absolute risk aversion degree $u=-e^{\rho w}$, which $\rho$ represents the audit department's risk aversion degree, which is the monetary income of the audit department $w$. The qualified effect of the audit department is $w_{0}$.

Assumption 5: assume that only the level of effort of audit departments is private and the rest is common knowledge.

\subsubsection{Model construction}

Government revenue can be expressed as: Since the Government is risk-neutral, the expected utility of the Government is equal to the expected revenue:

$$
V=E(\pi-S(\pi))=(1-\beta)(\pi-\alpha)
$$

The audit department is risk-averse and its monetary income may be expressed as:

$$
W=S(\pi)-C(a)=\alpha+\beta(\pi-\alpha)-0.5 b e^{2}
$$

The deterministic equivalent income of the audit department is:

$C E=E(W)-0.5 \rho \beta^{2} \sigma^{2}=\alpha+\beta(e-\alpha)-0.5 b e^{2}-0.5 \rho \beta^{2} \sigma^{2}$

Of these, $0.5 \rho \beta^{2} \sigma^{2}$ is the cost of risk.

Therefore, the principal-agent model can be expressed as:

$$
\begin{gathered}
\max _{e, \alpha, \beta}(1-\beta)(e-\alpha) \\
\text { s.t. }(I R) \alpha+\beta(e-\alpha)-0.5 b e^{2}-0.5 \rho \beta^{2} \sigma^{2} \geq w_{0} \\
(I C) e=\frac{\beta}{b}
\end{gathered}
$$

By substituting participation constraints and incentive compatible constraints into objective functions, the above optimization problems can be reformulated as follows:

$$
\max _{\beta}(1-\beta) \frac{\beta}{b}-w_{0}+0.5 \frac{\beta^{2}}{b}-0.5 \rho \beta^{2} \sigma^{2}
$$

The first order optimal condition is used to obtain: $\beta^{*}=\frac{1}{1+b \rho \sigma^{2}}$ So you can get to: $e^{*}=\frac{1}{b\left(1+b \rho \sigma^{2}\right)}$, $\alpha^{*}=\frac{w_{0}\left(1+\rho b \sigma^{2}\right)}{b \rho \sigma^{2}}-\frac{1-\rho b \sigma^{2}}{2 \rho b^{2} \sigma^{2}\left(1+\rho b \sigma^{2}\right)}$ at this point, the expected revenue of the audit department $E S(\pi)^{*}=w_{0}+\frac{1}{2 b\left(1+b \rho \sigma^{2}\right)}$, the utility of the government $V^{*}=\frac{1}{2 b\left(1+b \rho \sigma^{2}\right)^{2}}-w_{0}$.
(3) Model analysis

Conclusion 1: from $e^{*}=\frac{\beta^{*}}{b}$ and $b>0$ know, the audit department's effort level $e^{*}$ is directly proportional to the incentive intensity $\beta^{*}$, so the government can improve the audit department's effort level by increasing the incentive reward.

$$
\text { Conclusion 2: } \quad \frac{\partial \beta^{*}}{\partial \sigma}=-\frac{2 \rho b \sigma}{\left(1+b \rho \sigma^{2}\right)^{2}}<0
$$

$\frac{\partial e^{*}}{\partial \sigma}=\frac{1}{b} \frac{\partial \beta^{*}}{\partial \sigma}<0 \quad ; \quad \frac{\partial S(\pi)^{*}}{\partial \sigma}=\frac{1}{2 b} \frac{\partial \beta^{*}}{\partial \sigma}<0$

$\frac{\partial V^{*}}{\partial \sigma}=\frac{1}{2 b} \frac{\partial \beta^{*}}{\partial \sigma}<0$ the intensity of incentive $\beta^{*}$, the level of effort of audit department $e^{*}$, the expected income $\operatorname{ES}(\pi)^{*}$, the utility of government $V^{*}$ and the variance $\sigma^{2}$ of exogenous random variable $\varepsilon$ are inversely proportional, so the government should know the work of audit department as much as possible. To reduce the degree of information asymmetry (i.e. the variance $\sigma^{2}$ strength of exogenous random variables $\varepsilon$ ).

Conclusion $3: \quad \frac{\partial \beta^{*}}{\partial b}=-\frac{\rho \sigma^{2}}{\left(1+b \rho \sigma^{2}\right)^{2}}<0$

$$
\frac{\partial e^{*}}{\partial b}=\frac{1}{b} \frac{\partial \beta^{*}}{\partial b}<0 \quad ; \quad \frac{\partial S(\pi)^{*}}{\partial b}=\frac{1}{2 b} \frac{\partial \beta^{*}}{\partial b}-\frac{\beta^{*}}{2 b^{2}}<0
$$

$\frac{\partial V^{*}}{\partial b}=\frac{1}{2 b} \frac{\partial \beta^{*}}{\partial b}-\frac{\beta^{*}}{2 b^{2}}<0$ the intensity of incentive $\beta^{*}$, the level of effort of audit department $e^{*}$, the expected income $E S(\pi)^{*}$, the utility of government $V^{*}$ and the parameter of cost of effort $b$ are inversely proportional, therefore, the audit department with high qualification, ability and reputation, that is $b$ should be smaller.

$$
\text { Conclusion 4: } \frac{\partial \beta^{*}}{\partial \rho}=-\frac{b \sigma^{2}}{\left(1+b \rho \sigma^{2}\right)^{2}}<0
$$

$$
\frac{\partial e^{*}}{\partial \rho}=\frac{1}{b} \frac{\partial \beta^{*}}{\partial \rho}<0 \quad ; \quad \frac{\partial S(\pi)^{*}}{\partial \rho}=\frac{1}{2 b} \frac{\partial \beta^{*}}{\partial \rho}<0
$$

$\frac{\partial V^{*}}{\partial \rho}=\frac{1}{2 b} \frac{\partial \beta^{*}}{\partial \rho}<0$ the intensity of incentive $\beta^{*}$, the level of effort of audit department $e^{*}$, the expected income $\operatorname{ES}(\pi)^{*}$, the utility of government $V^{*}$ a nd the degree of risk aversion $\rho$ of audit department are inversely proportional to each other,that is, $\rho$ is smaller.

Obviously, participation constraint is a nonlinear optimization problem. If we solve it directly, it is a very complicated process. Therefore, we do the following analysis: the government employs third-party organizations to audit the audit departments, the government needs to pay a certain amount of supervision and audit costs, and expect to improve the quality of audit departments through third-party supervision. Third party organizations through audit supervision efforts to reduce the information asymmetry between the government and the audit department, thus effectively 
help the government to avoid some unnecessary losses, these saved losses is the expected effectiveness of the government. Similarly, the government has to pay a price for the audit and supervision of third-party organizations, which is the expected expenditure of the government. The higher the government's expected expenditure, the higher the level of oversight efforts of third-party organizations and the higher the effectiveness of government expectations; if the government's expected expenditure is lower, the level of oversight efforts of third-party organizations is lower. The less effective the government's expectations are. However, if the government only pursues a higher level of audit and supervision efforts, it may lead to the result that the gain is not worth the loss. This is because if the Government substantially increases its expected expenditure, the expected utility of the Government may increase only slightly according to the principle of diminishing utility. Therefore, the government needs to choose a balance point between expected expenditure and expected utility to maximize the difference between expected utility and expected expenditure. At the level of optimal oversight of third-party organizations, the government can derive the maximum benefit from the corresponding optimal distribution programme.

\section{CONCLUSIONS}

Based on the principal-agent theory in game theory, this paper establishes the principal-agent model between government and audit organization without considering the third party supervision, and analyzes the analytical solutions under various hypothetical conditions. It provides the basis for the government to formulate the optimal incentive policy. In addition, the principal-agent model between government, audit organization and third-party supervision unit is established under the consideration of third-party audit supervision. By adjusting the probability distribution of exogenous random variables, the corresponding analytical solution is obtained. Thus, it is effective to prove that in the process of major project audit, independent third party units are introduced to supervise and audit, It can affect the audit behavior of the audit department, thus better eliminate the information asymmetry between the government and the audit department, and create higher audit value and engineering audit quality for the government.

\section{References}

1. Calder Doug A $\mathbf{J}$. Construction quality auditing.Journal of Management in Engineering, 1997, 13( 6) : 26-28 .

2. Jergeas, George F.Mctague, Robert.Construction productivity:An auditing and measuring tool.46th Annual Meeting of AACE International, Jun2326,2002, Portland, OR, United States

3. Wyse Donald D, Malik Saahil . Audit contract provisions and real-time cost reporting in construction contracting . Journal of Professional Issues in Engineering Education and Practice, 2005, 31( 4) : 297-300 .

4. Khaled Al-Reshaid, Devil Cartam, Narendra Tewari, et al. A project control process in preconstruction phases: Focus on effective methodology. Engineering, Construction and Architectural Management,2005,12(4):351-372

5. Alexia Nalewaik. Construction Audit - An Essential Project Controls Function.AACE international transactions.CSC, Cost Engineering, 2007,49(10):20-27 